\title{
Hepatocarcinoma with metastasis to the anterior mediastinum
}

\author{
Rogério Camargo Pinheiro Alves ${ }^{1}$, Lorena Sagrilo Auer ${ }^{2}$, Lisa Rodrigues da Cunha Saud ${ }^{2}$, Raquel Coris Arrelaro², \\ Aline Carboni Casado², Bruno Gustavo Ferreira ${ }^{2}$, Denis Szjenfeld ${ }^{3}$, Paula Bechara Poletti ${ }^{2}$
}

${ }^{I}$ Department of Hepatology, Instituto de Assistência Médica ao Servidor Público Estadual, 04028-000 São Paulo, Brazil

${ }^{2}$ Department of Gastroenterology, Instituto de Assistência Médica ao Servidor Público Estadual, 04028-000 São Paulo, Brazil

${ }^{3}$ Department of Radiology, Instituto de Assistência Médica ao Servidor Público Estadual, 04028-000 São Paulo, Brazil

Correspondence to: Dr. Rogério Camargo Pinheiro Alves, Department of Hepatology, Instituto de Assistência Médica ao Servidor Público Estadual, Av. Ibirapuera, 981, Indianópolis, 04028-000 São Paulo, Brazil. E-mail: rcpalves@uol.com.br

How to cite this article: Alves RCP, Auer LS, da Cunha Saud LR, Arrelaro RC, Casado AC, Ferreira BG, Szjenfeld D, Poletti PB. Hepatocarcinoma with metastasis to the anterior mediastinum. Hepatoma Res 2016;2:293-6.

Article history:

Received: 22-01-2016

Accepted: $13-10-2016$

Published: $21-10-2016$

\section{Key words:}

Hepatocellular carcinoma,

mediastinal metastasis,

sorafenib,

computed tomography

\section{ABSTRACT}

Liver malignancies are the sixth leading cause of cancer worldwide, whereas hepatocellular carcinoma (HCC) is the most frequent histological type of liver cancer. Extrahepatic metastasis, which rarely involves the mediastinum, is associated with poor prognosis. An 80-year-old male presenting with mild diffuse abdominal pain for 4 months, associated with hyporexia, increased abdominal volume, dry cough, and loss of $4 \mathrm{~kg}$ in 1 month, sought medical assistance due to hemoptysis and chest pain. Tomographic study revealed HCC with mediastinal metastasis, after which sorafenib therapy was started. Disease progressed to death 4 months after the start of the treatment.

\section{INTRODUCTION}

Hepatocellular carcinoma (HCC) has high incidence and mortality rates, being the most common primary liver cancer ${ }^{[1]}$ and the third leading cause of cancer mortality. It usually starts with a solitary encapsulated lesion that often shows slow growth and is asymptomatic for a long time. ${ }^{[2]} \mathrm{HCC}$ is usually associated with liver cirrhosis, which may impair treatment tolerability and thus increase the risk of complications in cases of advanced cirrhosis. Although there are great differences in the global incidence and frequency of coexisting $\mathrm{HCC}$ and cirrhosis that vary according to ethnicity, the coexistence of these two conditions has the same basic clinical characteristics and leads to poor prognosis, regardless of race and location. ${ }^{[2]}$

Liver cirrhosis of any etiology and chronic infection by hepatitis $B$ are the main risk factors for the development of HCC. All patients with these two conditions benefit from biannual screening for HCC with abdominal ultrasound and measurement of alphafetoprotein (AFP) levels, although the latter has been shown to have questionable efficacy in population surveillance. ${ }^{[3,4]}$ 
Non-invasive diagnosis is made by imaging techniques, such as computed tomography and/ or magnetic resonance imaging, ${ }^{[4]}$ based on the vascular findings for these tumors, which exhibit a hypervascular pattern during the arterial phase and a washout pattern during the portal venous or delayed phase. Such radiological characteristic occurs in a small number of 1-2 cm tumors. In these cases, biopsy and tissue biomarkers, such as AFP, are used to confirm the diagnosis. Disease staging should be established at this point, in order to plan treatment and assess prognosis. ${ }^{[3,4]}$

The most frequent location of metastatic HCC is the lungs, due to possible hematogenous dissemination through their capillary network, followed by bones and abdominal lymph nodes. Conversely, mediastinal metastasis is an uncommon manifestation of HCC and shows poor prognosis. ${ }^{[5,6]}$ We present a case of an elderly patient admitted to our institution after being diagnosed with HCC and mediastinal metastasis.

\section{CASE REPORT}

This is the case report of an 80-year-old retired widower coming from São Paulo, southeastern Brazil. His past medical history included high blood pressure, dyslipidemia, diabetes mellitus, benign prostatic hypertrophy, and osteopenia. He was a former smoker of 90 packs a year and denied alcohol abuse. Four months before admission, the patient started to present with mild diffuse abdominal pain, hyporexia, increased abdominal volume, dry cough, anterior chest pain, and loss of $4 \mathrm{~kg}$ in the last mouth. He sought medical assistance after two episodes of hemoptysis.

A tomographic study revealed a contrast-enhanced expansive heterogeneous mass measuring $9.7 \mathrm{~cm} \times$ $5.1 \mathrm{~cm} \times 5.6 \mathrm{~cm}$ at this largest diameter and located on the left midline of the anterior mediastinum, with no clear interface between mediastinum and pericardium. No mediastinal lymphadenomegaly was detected. There were hepatic lesions showing a washout pattern in segments V, VI, VII, VIII and IV and protruding toward the hepatic hilum. Evidence of splenic vein thrombus was found [Figure 1].

Laboratory findings were as follows: hemoglobin $=10.5 \mathrm{~g} / \mathrm{dL}$; hematocrit $=34 \%$; leukocytes $=$ $7,500.000 / \mathrm{mm}^{3}$ (segmented: $64 \%$, band cells: $0 \%$, lymphocytes: $28 \%$, eosinophils: $5 \%$, monocytes: $3 \%$, basophils: $1 \%$ ); total bilirubin $=0.7 \mathrm{mg} / \mathrm{dL}$; alanine aminotransferase $=48 \mathrm{U} / \mathrm{L}$; aspartate aminotransferase $=40 \mathrm{U} / \mathrm{L} ; \mathrm{AFP}=14,000 \mathrm{ng} / \mathrm{mL}$; gamma-glutamyl transferase $=350 \mathrm{U} / \mathrm{L}$; alkaline
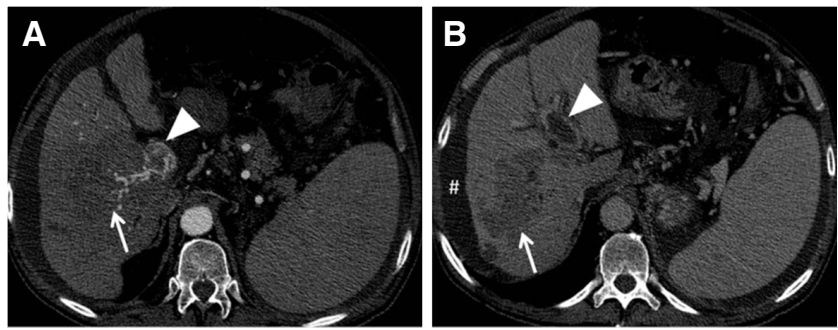

Figure 1: Axial contrast-enhanced computed tomography slices at arterial (A) and portal (B) phases. Note tumor infiltration (arrow) extending from part of the right hepatic lobe to the hilar region and tumor infiltration of the portal vein (arrow head)
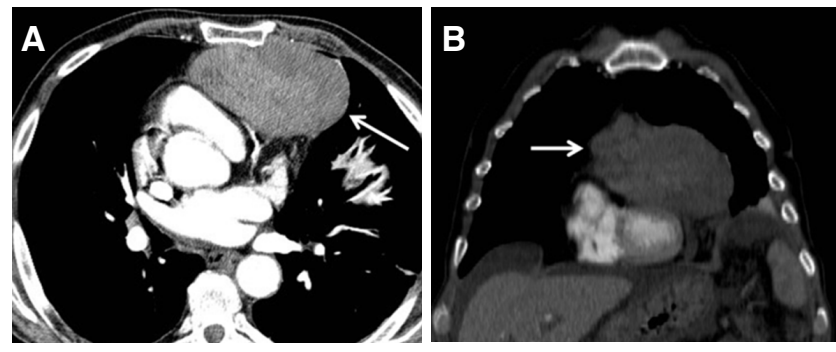

Figure 2: Axial contrast-enhanced computed tomography (CT) slice (A) and coronal reconstruction of CT scan (B). Note large heterogeneous hypervascular anterior mediastinal mass (arrow) posteriorly compressing the right atrium and pulmonary artery

phosphatase $=148 \mathrm{U} / \mathrm{L}$; international normalized ratio $=1.75$; creatinine $=0.77 \mathrm{mg} / \mathrm{dL}$.

The patient and his family decided to start sorafenib therapy, and he did not want to undergo invasive procedures, such as chemoembolization, for the treatment of mediastinal metastasis. Drug therapy was maintained for 3 months, when the patient was readmitted due to clinical worsening, with the development of jaundice and severe ascites. Patient staging was reassessed, showing evidence of growth of the mediastinal mass, which measured $11.0 \mathrm{~cm} \times$ $6.3 \mathrm{~cm} \times 7.7 \mathrm{~cm}$ at that time and was compressing the right atrium and the pulmonary artery [Figure 2]. There was also an increase in the size of hepatic solid lesions and in the extension of thrombosis. AFP levels reached $45,000 \mathrm{ng} / \mathrm{mL}$. It was decided to discontinue chemotherapy with sorafenib, and the patient died 1 month after readmission.

\section{DISCUSSION}

$\mathrm{HCC}$ is one of the most common primary tumors worldwide, and its prognosis has improved over the past few decades with the assessment of tumor vascular pattern by imaging methods and the emergence of therapeutic procedures. A considerable amount of literature has been published on the different presentations of $\mathrm{HCC}$ and on extrahepatic metastases, which occur in $30-50 \%$ of HCC cases. The most common metastatic sites are lungs, bones, 
Table 1: Cases of mediastinal metastases reported in the literature

\begin{tabular}{|c|c|c|}
\hline Ref. & Case report & Treatment \\
\hline Chiou et al. ${ }^{[9]}$ & $\begin{array}{l}\text { Patient with } \mathrm{HCC} \text { of } 8.6 \mathrm{~cm} \text { in segment } 4 \text { liver, underwent transcatheter arterial } \\
\text { embolization and following the appearance of mediastinal injury of } 4 \mathrm{~cm} \text { in the right } \\
\text { paratracheal region }\end{array}$ & Surgical ressection \\
\hline Shinya et al. ${ }^{[10]}$ & $\begin{array}{l}3 \text { lesions of HCC, } 2 \text { years after liver transplant tumor recurrence in the upper } \\
\text { mediastinum }\end{array}$ & Surgical ressection \\
\hline Huang et al. ${ }^{[13]}$ & $\begin{array}{l}2 \text { patients with hepatitis-C related HCC, after several courses of TACE developed } \\
\text { mediastinal and pericardial neoplastic growth }\end{array}$ & Radiotherapy \\
\hline Chen et al..$^{[14]}$ & $\begin{array}{l}\text { HCC } 3 \mathrm{~cm} \text { treated with TACE; } 2 \text { years after presents hoarseness, a chest CT scan } \\
\text { revealed a } 5-\mathrm{cm} \text { tumor over the aortopulmonary window of the mediastinum }\end{array}$ & TACE \\
\hline Oncale et al. ${ }^{[15]}$ & $\begin{array}{l}\text { HCC with liver mass } 11 \mathrm{~cm} \times 13 \mathrm{~cm} \text { with vena cava invasion and extension to the right } \\
\text { atrium }(4 \mathrm{~cm} \times 4 \mathrm{~cm})\end{array}$ & Sorafenib \\
\hline Sung et al. ${ }^{[16]}$ & $\begin{array}{l}\text { HCC with associated thrombus was found to extend from the liver through the inferior } \\
\text { vena cava into the right atrium }\end{array}$ & Surgical ressection \\
\hline Masci et al. ${ }^{[17]}$ & $\begin{array}{l}\text { Right intraventricular metastasis from HCC in a patient who had undergone a partial } \\
\text { hepatectomy for HCC more than two years earlier }\end{array}$ & $\begin{array}{l}\text { Systemic chemotherapy with } \\
\text { cisplatin and doxorubicin }\end{array}$ \\
\hline Ulus et al. ${ }^{[18]}$ & $\begin{array}{l}\text { HCC who was incidentally found to have an intracavitary mass completely occupying the } \\
\text { right atrium }\end{array}$ & Surgical resection \\
\hline Tastekin et al. ${ }^{[19]}$ & $\begin{array}{l}\text { HCC with hepatectomy; } 1 \text { year after patient started to present dyspnea, hoarseness, } \\
\text { palpitation, chest CT scan showed a mass of } 4 \mathrm{~cm} \text { in the left heart ventricle and } \\
\text { myocardial invasion }\end{array}$ & Surgical ressection \\
\hline Lei et al. ${ }^{[20]}$ & $\begin{array}{l}\text { The first patient was noted to have a large RV tumor mass with intracavitary growth and } \\
\text { myocardial invasion; the second had massive pulmonary and LA metastasis; and the } \\
\text { third patient had a right atrial tumor mass with concomitant RV and LA involvement }\end{array}$ & \\
\hline Fukuoka et al. ${ }^{[21]}$ & $\begin{array}{l}\text { Patient with pulmonary metastases from HCC, who presented with a tumor in the left } \\
\text { lung, extending to the left atrium through the left pulmonary vein }\end{array}$ & Sorafenib \\
\hline
\end{tabular}

HCC: hepatocellular carcinoma; TACE: transcatheter arterial chemoembolization; RV: right ventricular; LA: left atrial

and loco-regional lymph nodes, presenting commonly with dyspnea and bone pain. ${ }^{[7]} \mathrm{A}$ study in autopsy files showed that unusual extrahepatic metastatic sites include diaphragm, pancreas, gall bladder, stomach, colon, adrenal gland, pleura, peritoneum, cervical lymph nodes, brain, skin, and oral cavity. ${ }^{[8]}$

It is important to emphasize that the diagnosis of our patient was based on the presence of mediastinal mass and hepatic lesions. We decided not to perform liver biopsy because an imaging study revealed that the tumor had a washout vascular pattern and the patient showed AFP levels of $14,000 \mathrm{ng} / \mathrm{mL}$.

The involvement of mediastinal lymph nodes occurs in $4 \%$ to $5 \%$ of the cases of HCC. In patients with mediastinal metastasis, lesions were mostly diagnosed simultaneously with the viable intrahepatic tumor. ${ }^{[9]}$ Mediastinal metastases are unusual, and mediastinal involvement usually leads to dissemination to lymph nodes, which occurs by three routes of hepatic lymphatic drainage. The first route is from the left hepatic lobe via anterior phrenic lymph nodes to the parasternal or subcarinal lymph nodes; the second, from the liver through the hepatic falciform ligament to the parasternal or paratracheal lymph nodes; and the third, from the right hepatic lobe through the right triangular ligament to the paratracheal lymph nodes. ${ }^{[9,10]}$
The predictors of the presence of extrahepatic metastases are: size and number of HCC nodules, presence of tumor vascular invasion or tumor biomarkers. ${ }^{[2]}$

Patients with initial HCC, i.e. with no distant metastases, may undergo partial liver resection, which is potentially curative, as well as liver transplantation or percutaneous ablation. More advanced cases, such as the one presented in this study, are eligible to palliative treatment with sorafenib. ${ }^{[4]}$ However, research has shown that treatment of intrahepatic lesions should not be contraindicated in the presence of extrahepatic metastasis. Moreover, radical treatments for extrahepatic metastases should be considered when hepatic lesions are under reasonable control or if metastasis is accompanied by severe symptoms. ${ }^{[11,12]}$ In the case of mediastinal metastasis, transarterial chemoembolization has shown good response and adequate symptom control, in addition to increasing survival. ${ }^{[13,14]}$ In Table 1, we detail HCC cases of mediastinal metastases reported in the literature.

The present study showed that, despite therapeutic advances and the use of target therapy, survival is very limited when tumor is advanced, diagnosis is made at a later stage, and there are distant metastases.

\section{Financial support and sponsorship}

None. 


\section{Conflicts of interest \\ There are no conflicts of interest.}

\section{Patient consent}

Consent form was obtained from the patient family.

\section{Ethics approval}

The study was approved by the Institutional Review Board of IAMSPE.

\section{REFERENCES}

1. Vilana R, Forner A, Garcia A, Ayuso C, Bru C. Hepatocellular carcinoma: diagnosis, staging, and treatment strategy. Radiologia 2010;52:385-98. (in Spanish)

2. Okuda K, Ohtsuki T, Obata H, Tomimatsu M, Okazaki N, Hasegawa H, Nakajima Y, Ohnishi K. Natural history of hepatocellular carcinoma and prognosis in relation to treatment. Study of 850 patients. Cancer 1985;56:918-28.

3. Achkar JP, Araya V, Baron RL, Marsh JW, Dvorchik I, Rakela J. Undetected hepatocellular carcinoma: clinical features and outcome after liver transplantation. Liver Transpl Surg 1998;4:477-82.

4. European Association for the Study of the Liver; European Organization for Research and Treatment of Cancer. EASL-EORTC clinical practice guidelines: management of hepatocellular carcinoma. $J$ Hepatol 2012;56:908-43.

5. Kanda M, Tateishi R, Yoshida H, Sato T, Masuzaki R, Ohki T, Imamura J, Goto T, Yoshida H, Hamamura K, Obi S, Kanai F, Shiina S, Omata M. Extrahepatic metastasis of hepatocellular carcinoma: incidence and risk factors. Liver Int 2008;28:1256-63.

6. Katyal S, Oliver JH 3rd, Peterson MS, Ferris JV, Carr BS, Baron RL. Extrahepatic metastases of hepatocellular carcinoma. Radiology 2000;216:698-703

7. Uka K, Aikata H, Takaki S, Shirakawa H, Jeong SC, Yamashina K, Hiramatsu A, Kodama H, Takahashi S, Chayama K. Clinical features and prognosis of patients with extrahepatic metastases from hepatocellular carcinoma. World J Gastroenterol 2007;13:414-20.

8. Terada T, Maruo H. Unusual extrahepatic metastatic sites from hepatocellular carcinoma. Int J Clin Exp Pathol 2013;6:816-20.
9. Chiou SR, Lin TL, Bora D, Lu HI, Chen CL, Wang SH, Lin CC, Liu YW, Yong CC, Li WF, Liu CY, Wang CC. Metastatic hepatocellular carcinoma mimicking a solitary mediastinal tumor. $J$ Cancer Res Pract 2010;26:257-62

10. Shinya S, Noritomi T, Yamauchi Y, Sasaki T, Hamada Y, Yamashita Y. Two rare metachronous metastases of hepatocellular carcinoma after liver transplantation. Int Surg 2013;98:432-6.

11. Uchino K, Tateishi R, Shiina S, Kanda M, Masuzaki R, Kondo Y, Goto T, Omata M, Yoshida H, Koike K. Hepatocellular carcinoma with extrahepatic metastasis: clinical features and prognostic factors. Cancer 2011;117:4475-83.

12. Shimada M, Takenaka K, Gion T, Fujiwara Y, Kajiyama K, Maeda T, Shirabe K, Nishizaki T, Yanaga K, Sugimachi K. Prognosis of recurrent hepatocellular carcinoma: a 10-year surgical experience in Japan. Gastroenterology 1996;111:720-6.

13. Huang CC, Ng WW, Chiang JH, Chen FH, Huang CH, Wang YJ, Chang FY, Lee SD. Hepatocellular carcinoma with mediastinal and pericardial invasion: report of two cases. Zhonghua Yi Xue Za Zhi (Taipei) 1999;62:891-5.

14. Chen CC, Yeh HZ, Chang CS, Ko CW, Lien HC, Wu CY, Hung SW Transarterial embolization of metastatic mediastinal hepatocellular carcinoma. World J Gastroenterol 2013;19:3512-6.

15. Oncale M, Lewis B. Hepatocellular carcinoma with extension to the heart via the inferior vena cava. Proc (Bayl Univ Med Cent) 2015;28:229-30.

16. Sung AD, Cheng S, Moslehi J, Scully EP, Prior JM, Loscalzo J. Hepatocellular carcinoma with intracavitary cardiac involvement: a case report and review of the literature. Am J Cardiol 2008;102:643-5.

17. Masci G, Magagnoli M, Grimaldi A, Covini G, Carnaghi C, Rimassa L, Santoro A. Metastasis of hepatocellular carcinoma to the heart: a case report and review of the literature. Tumori 2004;90:345-7.

18. Ulus T, Birdane A, Dündar E, Tünerir B. Asymptomatic course of a metastatic mass completely filling the right atrium in a patient with hepatocellular carcinoma. Turk Kardiyol Dern Ars 2012;40:52-4.

19. Tastekin E, Usta U, Ege T, Kazindir G, Kutlu AK. Cardiac metastasis of hepatocellular carcinoma in a young non-cirrhotic patient, to the left ventricle. Ann Hepatol 2012;11:392-4.

20. Lei MH, Ko YL, Kuan P, Lien WP, Chen DS. Metastasis of hepatocellular carcinoma to the heart: unusual patterns in three cases with antemortem diagnosis. J Formos Med Assoc 1992;91:457-61.

21. Fukuoka K, Masachika E, Honda M, Tsukamoto Y, Nakano T. Isolated metastases of hepatocellular carcinoma in the left atrium, unresponsive to treatment with sorafenib. Mol Clin Oncol 2015:3:397-9. 